\title{
Valoraciones discursivas en torno a la discusión acerca del matrimonio igualitario en Chile*
}

\author{
Claudio Araya Seguel ${ }^{* *}$ \\ Javier González Riffo***
}

\section{Resumen}

En los últimos años se han producido cambios jurídicos que buscan un nuevo trato hacia la comunidad LGBTI (lesbianas, gay, bisexuales, transexuales e intersexuales) en Chile. Sin embargo, la discusión sobre el Matrimonio Igualitario sigue entrampada tanto en el debate legislativo como en la opinión pública. Desde la perspectiva del modelo de VALORACIÓN (Martin y White, 2005), se busca revelar los posicionamientos ideológicos de quienes promueven dicha ley y de quienes son sus detractores a través del análisis de dos cartas al director. Entre los principales resultados se puede mencionar la marcada contraposición de los recursos de monoglosia y heteroglosia en los textos en contra y a favor del Matrimonio Igualitario.

Palabras clave: Discurso, Valoración, Lingüística Sistémico-Funcional, Matrimonio Igualitario, Cartas al director.

\section{Discourse evaluations regarding same sex marriage discussion in Chile}

\begin{abstract}
In recent years some legal changes that seek a new deal towards LGBTI have occurred . However, the discussion on gay or same-sex marriage is stagnated in both the legislative debate and public opinion. From the perspective of the Appraisal theory (Martin and White, 2005), the aim is to identify the ideological stances of those in favor and those against this law through the analysis of two letters to the editor. Some of the main results include a) the notorious contrast of monoglossic and heteroglossic resources used in the letters: one referring to received truths and the other resorting to historical evidence; b) the recurrence of empowering and disempowering strategies to define institutional conflicts; and c) strategies that legitimize their own stances.
\end{abstract}

Key Words: discourse, appraisal, sistemic Functional Linguistics, same-sex marriage, letters to the editor.

Recibido: 12/07/2018

Aceptado: $26 / 11 / 2018$

Este artículo corresponde a los resultados parciales de la Tesis Doctoral Concepciones ideológicas acerca de la comunidad gay desde sus representaciones discursivas en ciberprensa chilena, adscrita al programa de Doctorado en Lingüística, Facultad de Letras, de la Universidad Católica de Chile. Su autor, Claudio Araya Seguel, es becario Conicyt.

** Chileno. Dr.@ Lingüística, Universidad Católica de Chile, Santiago, Chile. claurayas@gmail.com

*** Chileno. Magíster en Lingüística, Universidad Católica de Chile, Santiago, Chile.jdgonzalez@uc.cl 


\section{Introducción}

En los últimos años la sociedad chilena se ha abierto a la discusión de temas que generan controversia, como lo demostró la promulgación del AUC (Acuerdo de Unión Civil), de la Ley Antidiscriminación y la reciente (2016) presentación al Gobierno de proyectos de Matrimonio Igualitario. Uno de esos temas controversiales es la diversidad sexual y, más concretamente, la regulación legal de las parejas del mismo sexo que conviven y que han construido familia. En efecto, encuestas como Cadem (2015) han demostrado que, pese a que la mayoría de los chilenos en la actualidad está de acuerdo con una eventual aprobación de una ley de Matrimonio Igualitario, sigue habiendo un disenso no menor ${ }^{1}$.

Países sudamericanos como Colombia (2016), Brasil (2013), Uruguay (2013) y Argentina (2010) han legalizado el Matrimonio Igualitario y han marcado un camino en torno al respeto por la diversidad sexual amparado a su vez en la necesidad de trato igualitario de las personas ante la ley, tal como se establece en las constituciones de aquellos países (incluyendo la chilena, por cierto). En Chile, debido a la ausencia de una ley que regule el matrimonio entre personas del mismo sexo, muchas personas de orientación homosexual simplemente son despojadas de sus pertenencias al morir sus parejas por parte de sus familias, las que rechazaban esos vínculos por razones religiosas o por la potencia de la heteronorma, a pesar de que a partir del crimen de Daniel Zamudio (cf. Fluxá, 2014) exista la denominada Ley Antidiscriminación. De acuerdo con Farías (2015), se observaría, entonces, una homofobia latente en la sociedad chilena.

Sin embargo, la discusión dentro de la sociedad chilena ha ido más lejos y, en este contexto, las agrupaciones representativas de la diversidad sexual han liderado el debate nacional respecto a la necesidad de equiparar el acceso a ciertas instituciones culturales como el matrimonio y ofrecer dicho acceso o posibilidad a todas las personas independientemente de su condición sexual.

En enero de 2017 la presidenta Bachelet, quien lideraba la coalición de centro izquierda Nueva Mayoría, encabezó un acto público en La Moneda que marca el inicio del proceso para el Matrimonio Igualitario. Dicho acto tiene un carácter reparatorio hacia las parejas conformadas por personas

Según la encuesta Cadem (2015), el 55\% de la población chilena se muestra a favor del Matrimonio Igualitario. En contraposición, un $36 \%$ se manifiesta en contra de legislar al respecto. 
de orientación homosexual a las que se les negó la posibilidad de contraer matrimonio en Chile, cuestión que llevó al MOVILH ${ }^{2}$ a presentar una demanda contra el Estado de Chile ante la Comisión Interamericana de Derechos Humanos (CIDH) en 2012. La demanda derivó en una solución amistosa a través de un acuerdo con el Gobierno en junio del año 2016. Pese a esto, se trata de una discusión aún abierta en la sociedad chilena, para lo cual los medios de comunicación han sido escenario de ese intercambio de opiniones sobre el Matrimonio Igualitario. Sin embargo, organizaciones de diversidad sexual como MOVILH e IGUALES han planteado sus reparos pues el Gobierno recién envía el proyecto de ley en el segundo semestre del año 2017 sin urgencia legislativa, por lo que es considerada una maniobra dilatoria que traspasa la responsabilidad al próximo Gobierno que asume en el año $2018^{3}$.

A partir de ese contexto, en este artículo analizamos dos cartas al director publicadas en emol.com (portal web de El Mercurio) que se refieren al Matrimonio Igualitario. Dichos textos presentan posicionamientos ideológicos contrapuestos y dialogan explícitamente entre sí, pues la segunda carta al director corresponde a una respuesta a la primera en tanto refutación de los argumentos esgrimidos en la carta de origen: en concreto, Álvaro Góngora, historiador miembro de la Academia Chilena de Historia, esgrima razones para estar en desacuerdo con una eventual aprobación del Matrimonio Igualitario, mientras que Luis Larraín, ex presidente de la fundación Iguales ${ }^{4}$, le responde con sus argumentos a favor. Estamos, por tanto, en presencia de dos textos que se relacionan por intertextualidad e interdiscursividad, siguiendo la perspectiva de Kristeva (1980) y Fairclough $(2008,2013)$, y que representan, en parte, dos visiones sobre cómo la temática del Matrimonio Igualitario debiera ser tratada en términos legislativos.

A partir de lo anterior, pretendemos examinar el posicionamiento ideológico de ambas visiones contrapuestas por medio de la observación de patrones valorativos expuestos en aquellas cartas al director. Para esto, nos planteamos dos objetivos de naturaleza específica: (1) comparar las estrategias valorativas presentadas en el corpus en estudio y (2) describir

Organización pro diversidad sexual, fundada en el año 1991. El significado de la sigla es 'Movimiento de integración y liberación homosexual'.

A fines del año 2017, la coalición de derecha 'Chile Vamos' gana las elecciones presidenciales y asume la presidencia Sebastián Piñera en marzo de 2018.

4 Iguales es una organización pro diversidad sexual fundada en el año 2010 en Chile. 
cómo se desarrolla el diálogo entre ambos discursos, entendiendo que uno es una respuesta a otro. En consecuencia, nos será capital tener en cuenta la noción de clave valorativa (Martin y White, 2005), para lo cual teórica y metodológicamente consideramos particularmente los sistemas semánticos propuestos en el lineamiento del modelo de VALORACIÓN (cf. White, 2004; Martin y White, 2005; Hood, 2010; Kaplan, 2004; Oteíza y Pinuer, 2012, entre otros), enmarcado más generalmente en los principios de la Lingüística Sistémico-Funcional (LSF). La relevancia de este análisis recae en la necesidad de constatar cómo dialogan dos visiones encontradas en el discurso de los medios de comunicación, esenciales para construir y reproducir ideologías, más aún en una discusión vigente en la sociedad chilena y que implica derechos fundamentales de ciudadanos y ciudadanas del país.

\section{Fundamentos teórico-conceptuales}

\subsection{De la subjetividad en el lenguaje}

La perspectiva bajtiniana del lenguaje plantea que la lengua en uso, vale decir, el discurso (Fairclough, 1992, 1995, 2013) es fundamentalmente interactiva y que, en consecuencia, esa es su esencia. Consecutivamente, Volóshinov (2009) toma distancia del formalismo y se alinea con una perspectiva lingüística propuesta por la LSF que concibe el lenguaje de forma estratificada en los niveles fonológico-grafológico, léxico-gramatical y discursivo-semántico, más los niveles más abstractos de registro y género; en la misma línea propuesta por Halliday (1978), quien señala que el lenguaje y el contexto guardan una relación dialéctica. De esta forma, se puede establecer -siguiendo a White (2010)- que todo texto hablado o escrito eminentemente es dialógico ${ }^{5}$.

Aquella cuestión, Volóshinov (citado por White, 2010) la plantea al señalar que la interacción verbal es la verdadera realidad del lenguaje, pues da cuenta de eventos sociales en los que los escritores o hablantes vislumbran y perfilan un potencial lector y con ello adelantan eventuales respuestas o buscan apoyos a sus posiciones ideológicas. Por tanto,

En efecto, White (2010), considerando las premisas bajtinianas, señala que la dialogicidad en el discurso obliga a considerar que en la interacción se presenta un destinatario pretendido con el que se construye el discurso propiamente tal, una relación entre los participantes y la consecuente alineación axiológica, y la manera en que se negocian posiciones. 
el texto se transforma en un repositorio de las intersubjetividades de escritores /hablantes y lectores/oyentes, pues en él se negocian posicionamientos, se expresan alineaciones axiológicas (White, 2010) o divergencias respecto a la observación de los eventos sociales.

Tal carácter dialógico del lenguaje, que sustenta desarrollos teóricos posteriores tales como el modelo de VALORACIÓN (Martin y White, 2005), enmarcado en el lineamiento de la Lingüística Sistémico Funcional queda en evidencia si se considera que todo escritor/hablante prefigura una direccionalidad del texto o un destinatario eventual (Addresivity) con el cual se establece una forma de relación en tanto predetermina ciertos tipos de respuestas. En este mismo sentido, los textos construyen destinatarios, vale decir, una virtualidad en la que sus participantes expresan ciertas suposiciones, experiencias y creencias. Asimismo, los autores escriben o hablan también para indicar una particular postura o relación con el destinatario eventual, un tipo de alineación axiológica (White, 2010) en cuanto al acuerdo o divergencia en el posicionamiento ideológico. La denominada comunalidad (White, 2010) se expresa de forma estrecha cuando las posiciones alternativas son excluidas, mientras que se manifiesta de forma amplia cuando ese posicionamiento alternativo es incluido en el texto. En ese escenario, comunalidad es un concepto que enriquece la comprensión del carácter dialógico de los sistemas de VALORACIÓN y, particularmente, del subsistema de COMPROMISO, que permite constatar discursos monoglósicos o heteroglósicos, es decir, discursos que excluyen posicionamientos alternativos (comunalidad estrecha), por una parte, y -por otra- discursos que incluyen posiciones ideológicas alternativas (comunalidad amplia). De esta manera, el subsistema de compromiso dice relación con cómo se construye al destinatario en el discurso y sus propias creencias ideológicas. En consecuencia, asumir este lineamiento implica situarse en un paradigma funcionalista, entendiendo al discurso como forma de participación social, y entendiendo que este y el contexto establecen una relación de constitución mutua -es decir, no unidireccional-.

Frente a este panorama surge la interrogante: ¿por qué la evaluación es relevante cuando se aborda la comunicación? Desde una perspectiva funcional, la importancia de la evaluación radica en que expresa las opiniones de los escritores/ hablantes y refleja el sistema de valores de su comunidad; construye y mantiene las relaciones entre escritores/hablantes y lectores/ oyentes; y, por último, organiza el discurso (Thompson y 
Hunston, 2000). Así, estos lineamientos evidencian que el lenguaje permite que las personas presenten sus ideas y, en consecuencia, sus propias identidades. Esas opiniones y creencias expresadas transmiten sistemas de valores comunes, incluso institucionalizados (Martin y White, 2005). Asimismo, estos sistemas de valores corresponden a la ideología que se patenta en todo un texto. Identificando qué es lo que el escritor o hablante piensa, se revela la ideología de la sociedad que ha producido el texto (Thompson y Hunston, 2000). En este sentido, los significados valorativos representarían también preceptos culturales al dilucidar cómo las comunidades a las que pertenecen los evaluadores valoran positiva 0 negativamente diferentes aspectos de la realidad con la que se relacionan.

De la misma forma, aquella relación entre el hablante y la realidad se puede evidenciar en la comunicación misma. En efecto, en la interacción, la evaluación puede ser utilizada para manipular al lector/ oyente, ya sea para persuadirlo o para que vea las cosas de determinada manera, como -por ejemplo- cuando los sucesos se plantean como problemas (Thompson y Hunston, 2000). En este sentido, por medio de la descripción de las estrategias valorativas también se podría examinar la línea argumental de las personas en sus construcciones discursivas.

\subsection{Sistema de VALORACIÓN}

Este trabajo se instala en el nivel discursivo semántico de la concepción estratificada de la LSF y, específicamente, explora la metafunción interpersonal en las cartas al director que conforman el corpus. En tal sentido, una perspectiva que profundiza en la metafunción interpersonal en el marco de la LSF es el modelo de VALORACIÓN (Martin y White, 2005). Este modelo examina la presencia subjetiva de los escritores/ hablantes y lectores / oyentes en los textos. El sistema de VALORACIón se preocupa de los recursos empleados por ellos para adoptar posiciones, aprobar y desaprobar, aplaudir y criticar sus propias posiciones y las de su contraparte. Además, el modelo da cuenta de los recursos a través de los cuales los escritores/hablantes construyen un destinatario y cómo se alinean o desalinean respecto a eventuales interlocutores. Dicho sistema semántico permite construir las identidades de los interlocutores. En este sentido, el modelo propone que la intersubjetividad es construida por los escritores / hablantes y lectores/ oyentes, quienes cumplen diversos roles sociales. De esta manera, se facilita el estudio de la codificación inscrita o evocada de la intersubjetividad en el discurso (Oteíza, 2017). 
Junto con lo anterior, el modelo de VALORACIÓN ofrece una forma de categorizar los significados interpersonales. Además, se ocupa de una perspectiva intersubjetiva social en evaluación y propone un complemento al estudio de la mirada de los significados interpersonales más allá del rango de la cláusula. La función de este sistema en el estrato semántico-discursivo de la lengua se debe fundamentalmente a que las realizaciones de una actitud se despliegan a lo largo del discurso: una actitud puede realizarse a través de una amplia gama de categorías gramaticales diferentes y puede realizarse de forma incongruente a través de metáforas gramaticales (Martin y White, 2005). En este sentido, y pese a que nos situamos en el plano semántico-discursivo del lenguaje, cabe destacar que para que la evaluación proceda como tal se requiere, lógicamente, de la codificación léxico-gramatical de la lengua, lo que evidencia la propiedad del sistema semiótico estratificado del lenguaje por medio de la relación de realización entre los ciclos de codificación.

El modelo de VALORACIÓN organiza la evaluación en tres sistemas o dominios semánticos: ACTITUD, GRADACIÓN y COMPROMISO. Esta evaluación se puede concretar de manera explícita o implícita (inscrita o evocada) y a lo largo del texto puede crear prosodia valorativa que emerge codificada en el nivel léxico-gramatical. En cuanto a esto, conviene precisar que, de acuerdo con el principio de metarredundancia, si bien la valoración es codificada en el estrato léxico-gramatical, da cuenta de una acumulación a lo largo del despliegue textual, es decir, en el estrato discursivo semántico.

En cuanto a los dominios del modelo, en sus aspectos generales, se puede señalar que la ACTITUD se concibe como la manera a través de la cual los sentimientos son vistos como un sistema de significados. De acuerdo con Martin y White (2005) el sistema de VALORACIÓN comprende tres áreas semánticas: AFECTO (expresiones de sentimientos positivos y /o negativos), JUICIO (puntos de vista en relación con los comportamientos de las personas) y apreciación (evaluaciones de fenómenos semióticos o naturales). Estos territorios semánticos codifican sentimientos, sin embargo, el afecto corresponde al sistema básico y los otros dos (JUICIO y APRECIACIÓN) corresponderían a sentimientos institucionalizados (Oteíza, 2017; Martin, 2003; Martin y White, 2005).

Por su parte, el subsistema de gradación se refiere a cómo las valoraciones pueden ser elevadas o bajadas en el discurso. Eso es posible 
por medio de recursos semánticos para intensificar o disminuir los significados (FUERZA) o bien podemos agudizar o suavizar los límites de una experiencia, fenómeno o actitud (FOCO). En definitiva, este subsistema gradúa las valoraciones que emergen en el texto y que se refieren a diversas entidades.

El subsistema de COMPROMISO se refiere a los recursos semánticos empleados para la negociación interpersonal y responden a una perspectiva dialógica que permite analizar las fuentes de origen de las actitudes y reconocer los discursos como monoglósicos o heteroglósicos, siguiendo la tradición iniciada por Volóshinov (2009 [1929]). La monoglosia corresponde a la exclusión en el discurso de posiciones alternativas, mientras que la heteroglosia hace referencia, por el contrario, a la inclusión de posiciones o voces alternativas en el discurso. Estos conceptos -en los términos de White (2010)- equivalen a comunalidad estrecha y amplia, respectivamente. En síntesis, el sistema de COMPROMISO tiene que ver con cómo se construye al destinatario en el discurso. Sin embargo, y como se verá más adelante, los subsistemas y sus consecuentes categorías no siempre son adecuadas para el análisis de cualquier discurso, dadas las particularidades que se presentan en estos. En aquel contexto, Oteíza y Pinuer (2012) ofrecen una propuesta que amplía el subsistema de APRECIACIÓN por medio de la inclusión de categorías que permiten dar cuenta de cómo trabaja la valoración cuando los objetos evaluados son eventos, situaciones y procesos históricos. Así, proponen las categorías de Integridad, Valuación [Impacto], Conflictividady Poder, las que evidencian la (des)legitimación discursiva de los objetos. De la misma forma, estos últimos también podrían ser evaluados desde los subsistemas de AFECTO. La siguiente figura sintetiza lo recién expuesto:

Figura 1. Propuesta de red de apreciación para la evaluación de eventos, situaciones y procesos históricos (Fuente: Oteíza y Pinuer, 2012).

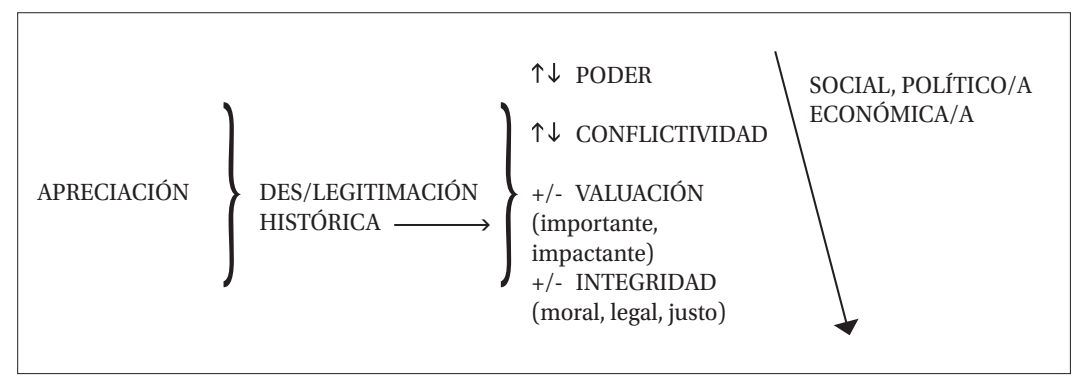


Desde la perspectiva de los Estudios del Discurso, se puede señalar que asumir analíticamente una mirada evaluativa del lenguaje nos permite aproximarnos a la comprensión de las intersubjetividades que se configuran en los textos. Al identificar las creencias, opiniones, emociones, juicios y apreciaciones expresados por los hablantes podemos acceder a las ideologías que subyacen al discurso y a los sistemas de creencias que operan en las comunidades a las que pertenecen los hablantes. Esto, además, da cuenta de cómo lingüísticamente se construyen las identidades sociales y cómo se despliegan en el discurso a través de los recursos valorativos. Así, el lenguaje evaluativo construye las imágenes sociales de quienes se comunican y delimita sus posicionamientos ideológicos referidos a diversos aspectos de la experiencia en el mundo.

\section{Metodología}

Metodológicamente, con el fin de cumplir con los objetivos indicados más arriba, el análisis se focalizará en el complejo clausular de las cartas al director que conforman el corpus, entendiendo que el texto es una unidad de análisis en tanto unidad semántica. Sin embargo -precisamos- el modelo de vALORACIÓN corresponde al estrato discursivosemántico, por lo que, si trabajamos a nivel léxico-gramatical, es para facilitar la progresión del análisis, pues las evaluaciones se van codificando en el nivel léxico-gramatical de la lengua y desplegando a lo largo del texto por acumulación.

Se procede a fragmentar los textos en complejos clausulares. Dichos textos se organizan en una grilla en la que se establecen las categorías graficadas en el siguiente cuadro ${ }^{6}$ :

Hemos trabajado con esta versión adaptada del trabajo de Oteíza, Henríquez y Canelo (2018), quienes a su vez se basan en Martin y White (2005). 
Cuadro 1. Grilla de análisis de textos que conforman el corpus. El cuadro incluye ejemplos.

\begin{tabular}{|c|c|c|c|c|c|}
\hline $\begin{array}{l}\text { Entidad } \\
\text { discursiva } \\
\text { valorada }\end{array}$ & VALORACIÓN & Discurso analizado & Actitud & СомрRоміso & GrADACIÓN \\
\hline Fijar verdades & $\begin{array}{l}\text { Peligroso } \\
\text { Inamovibles }\end{array}$ & $\begin{array}{l}\text { ¡Matrimonio } \\
\text { igualitario! } \\
\text { Luis Larraín: “es } \\
\text { peligroso fijar como } \\
\text { verdades inamo- } \\
\text { vibles a ciertos } \\
\text { comportamientos }\end{array}$ & $\begin{array}{l}\text {-va } \\
\text { APRECIACIÓN. } \\
\text {-va } \\
\text { APRECIACIÓN. }\end{array}$ & $\begin{array}{l}\text { Monoglosia. } \\
\text { Aserción. } \\
\text { Proceso rela- } \\
\text { cional x2. }\end{array}$ & $\begin{array}{l}\text { Fuerza. } \\
\text { Cuantificación } \\
\text { temporal } \\
\text { (largos). }\end{array}$ \\
\hline Verdades & $\begin{array}{l}\text { Legitimados por } \\
\text { el solo hecho de } \\
\text { serlos. }\end{array}$ & $\begin{array}{l}\text { históricos legiti- } \\
\text { mados por el solo } \\
\text { hecho de serlos. } \\
\text { Tanto la hegemonía } \\
\text { del hombre sobre }\end{array}$ & $\begin{array}{l}\text {-va } \\
\text { APRECIACIÓN. } \\
\text {-va }\end{array}$ & & \\
\hline Hegemonías & $\begin{array}{l}\text { Legitimadas } \\
\text { Incuestionables }\end{array}$ & $\begin{array}{l}\text { la mujer como la } \\
\text { del poderoso sobre } \\
\text { el desvalido han } \\
\text { estado legitimadas } \\
\text { por largos períodos, } \\
\text { lo cual no las hace } \\
\text { incuestionables". }\end{array}$ & $\begin{array}{l}\text { APRECIACIÓN. } \\
\text {-va } \\
\text { APRECIACIÓN. }\end{array}$ & & \\
\hline
\end{tabular}

El cuadro distingue algunas categorías conceptuales relevantes para este estudio. En primer lugar (de izquierda a derecha), se ubican las entidades discursivas valoradas, aspecto clave a discernir, pues, como se observa luego en el apartado 4, la línea argumental de cada posición establece relaciones claves con ciertas entidades que son evaluadas positiva o negativamente. A continuación, se establecen las inscripciones o evocaciones ${ }^{7}$ que dan cuenta de las valoraciones. En seguida se da cuenta del extracto de discurso examinado. Le siguen los sistemas propuestos desde el modelo de VALORACIÓN. Respectivamente: ACTITUD, COMPROMISO y GRADACIÓN. Este ordenamiento nos permite luego evaluar la globalidad de ambos textos en términos de qué y cómo se está evaluando. De esta forma, podemos describir la prosodia valorativa y discernir los principales contrastes entre ambos discursos.

Para conseguir lo anterior, en el análisis hemos seguido una notación que nos permite homogeneizar ciertos criterios, los que a su vez entregan un orden al análisis. En la grilla y los ejemplos tomados del corpus para el análisis, la notación se inscribe de acuerdo con los siguientes

Las valoraciones pueden aparecer en los textos de forma inscrita o evocada, de acuerdo con el modelo. Emergen de forma inscrita cuando aparece codificada de manera explícita, mientras que las valoraciones evocadas se expresan de forma implícita y, en este caso, será relevante el contexto lingüístico para poder dilucidarlas. 
criterios: se utiliza negrita para destacar las valoraciones discursivas; si esta es evocada, además se le agrega cursiva. Para la GRADACIÓN, si se identifica un recurso de FOCO, este aparece con cursiva y subrayado, mientras que el subrayado sin cursiva se utiliza para destacar los recursos de FUERZA. Consecutivamente, '-va’ y ‘+va’ permiten señalar la polaridad de la valoración: negativa y positiva, respectivamente. Asimismo, seguido a este elemento se señala el subsistema y su consiguiente detalle. Se ha seguido estos criterios en el análisis de ambos discursos. Luego, y considerando la unidad de cada uno, se han identificado los principales patrones en términos de los tres subsistemas junto con las entidades evaluadas. Por último, hemos contrastado esos resultados.

Los ejemplos que exponemos en este artículo son de las cartas al director analizadas y sirven para ilustrar los detalles que luego enunciamos.

\section{Análisis y discusión}

A continuación, presentamos aspectos de nuestro análisis. Como forma de organizar los resultados, articulamos su exposición en base a elementos temáticos.

\subsection{Matrimonio como institución y como idea}

Un primer aspecto relevante es cómo se aborda la idea de matrimonio, tanto el heteronormado como el potencial Matrimonio Igualitario, en los discursos. En este aspecto, los discursos nos proporcionan bastante evidencia lingüística, dado que es el objeto más evaluado en ambas columnas de opinión. Cabe destacar, incluso, que otros objetos evaluados son relacionables a este objeto, ya que se evalúan instituciones legislativas que aportan una visión y también personas que se ajustan a una u otra posición.

Uno de los aspectos destacados del análisis es el que Góngora da valor de institución al matrimonio heteronormado. Como tal, esto permite constantemente activar el sistema de JUICIO en el análisis, siendo juicios por capacidad los que usualmente se constataron:

(1) [El matrimonio heteronormado] Es la instancia por excelencia que funda la familia.

La idea de Góngora, tal como se observa en (1), descansa en que el matrimonio heteronormado es el único vínculo con la capacidad de 
formar una familia, entendida a esta desde una óptica tradicional, con un padre-hombre y una madre-mujer ${ }^{8}$. Este potencial de procreación es el que legitima a este tipo de matrimonio como el único viable, ya que este ha sido el criterio que se ha utilizado durante siglos para promover únicamente tal institución y no otra. Siguiendo ese lineamiento, como en una relación entre personas de orientación homosexual no puede haber procreación, entonces se ha de descartar el Matrimonio Igualitario.

Junto con lo anterior, Góngora se refiere al Matrimonio Igualitario siempre como una idea, como una abstracción, y no como a una potencial institución o, incluso, a una institución tal como sucede en otros países. Este hecho se complementa con que para aludir al Matrimonio Igualitario deba también constantemente referirse a quienes promueven esa idea, dado que la posibilidad de ese tipo de matrimonio se limita únicamente al resultado de una divagación intelectual, lo que contrastaría con el fin trascendente de la institución heteronormada y su virtud heredada por la naturaleza:

(2) [El matrimonio] Es una “construcción” biológica ajena a toda intervención intelectual.

Cabe destacar, entonces, que el matrimonio tal como solo puede ser en la actualidad en Chile se articula en base a un fin trascendente, reconocido espiritualmente por instituciones legitimadas como se revisará más adelante, y a una congruencia con la naturaleza. En este sentido, su posición se sintetiza en que Dios -o los distintos dioses, precisa- crea la naturaleza y es deber ético del hombre socializado seguir ese lineamiento. De igual forma, al conceptualizar el matrimonio como algo ajeno a la intervención intelectual, le resta agencia a quienes promueven el Matrimonio Igualitario, cuestión que contrasta con la respuesta de Larraín.

Larraín, por su parte, legitima al Matrimonio Igualitario como proceso histórico en tanto otros países lo han permitido legalmente. El fundamento de su posición favorable al Matrimonio Igualitario se basa en que, como otros procesos sociales, ha logrado convertirse en una realidad y constituye un valor de las sociedades democráticas modernas. Así, independiente al estado actual de la discusión en Chile, para Larraín

8 Góngora incluso señala: “... el matrimonio, la familia, la función que deben cumplir con los hijos el padre-hombre, la madre-mujer, doctrinariamente no cabe ser neutral”. 
el Matrimonio Igualitario es una potencial realidad y, en consecuencia, se trata de una institución aún no legitimada localmente.

Sumado a lo anterior, Larraín defiende no tan solo al Matrimonio Igualitario, sino también a la homosexualidad, lo que no es aludido por Góngora en su discurso. Para esto, en tanto, articula su defensa en base a la evidencia histórica:

(3) La historia nos muestra que, contrario a lo que algunos puedan pensar, tanto la homosexualidad como la formalización de las relaciones entre personas del mismo sexo forman parte no solo de la historia de la humanidad, sino también de la de nuestra propia cultura occidental, y no son síntomas de la posmodernidad.

En (3), Larraín se refiere a que, si se tratase de que es la historia la que legitima las instituciones y a las personas involucradas en ellas, entonces, habría evidencia -como presenta con posterioridad en su texto- para legitimar a las personas homosexuales y las uniones matrimoniales que estos querrían formar. En este sentido, aquellos JUICIOS por normalidad que eran propugnados por Góngora se vierten en el discurso de Larraín como positivos. En consecuencia, al situar el Matrimonio Igualitario como un movimiento social e histórico, les otorga a las personas una agencia que Góngora le había restado. La intervención intelectual no se evalúa negativamente en el discurso de Larraín.

\subsection{Importancia de la GRADACIÓN en los textos}

La GRADACIÓN cumple con el importante rol de aumentar o disminuir la fuerza de los significados interpersonales, así como también el de focalizar o difuminarlos. En este sentido, es clave revisar cómo este subsistema se presenta en los discursos analizados, dado que pueden dar cuenta de la articulación de la línea argumental de los emisores.

En la columna de opinión de Góngora, la gradación se presenta en una doble vertiente: las fuerzas altas se articulan en base a aquello que respalda su punto de vista, mientras que las bajas, en cambio, se las adjudica a aquello que es parte del punto de vista contrario. Los que siguen son ejemplos de esto:

(4) El matrimonio [heteronormado] es una relación de gran riqueza humana, pero su verdad antropológica más profunda es la unión abierta a la perpetuación de la especie. 
(5) [La causa del Matrimonio Igualitario es una] Bandera política acogida por partidos y gobiernos doctrinariamente "líquidos".

Como se observa, en (4) el objeto evaluado es el matrimonio heteronormado, mientras que en (5) se trata de evaluaciones al Matrimonio Igualitario. En el caso del primero, el autor utiliza formas aisladas (Hood, 2010) para fortalecer sus evaluaciones positivas, lo que es usual en toda su columna de opinión. Por el contrario, en (5) se utilizan lo que Hood (2010) denomina formas impregnadas; es decir, ítems léxicos que ya en su propio contenido semántico cuenta con una gradación. En este sentido, el uso de líquidos cumple con la función no tan solo de evocar una evaluación negativa (por la metáfora léxica presente), sino también de dar cuenta de un respaldo doctrinario que, a su parecer, es deficiente.

En el mismo contexto, Góngora recurre a instituciones y disciplinas para legitimar su postura. Para esto, la GRADACIÓN nuevamente es clave, puesto que con esta le da un aspecto totalizante a ellas, como se evidencia en los dos siguientes ejemplos:

(6) Para cristianos y católicos, Dios la instituyó con fines trascendentes y todas las religiones conocidas del mundo lo consagran.

(7) La etnología y antropología enseñan la existencia de una gama de matrimonios y formas familiares, pero todas son alianzas constituidas acorde con el modo de ser hombre y de ser mujer.

Si bien los elementos graduados son cuantificables mediante evidencia más concreta como números, Góngora prefiere realizar aquellas cuantificaciones mediante elecciones léxicas que dejen claro el aspecto totalizante que legitima su posición. Así, recurre a las religiones y a las pruebas revisadas antropológicamente como evidencia de que su parecer es el correcto.

La GRADACIÓN en la carta de Larraín es menos recurrente que en la de Góngora. En este caso, los recursos presentes son siempre de FUERZA por intensificación alta y de cuantificación por extensión temporal y espacial. Esto se podría deber a que el autor intenta por medio de estos recursos dar cuenta de que la aprobación del Matrimonio Igualitario se trata de un fenómeno extendido en el mundo y que parece ser inminente en Chile. El siguiente ejemplo ilustra esta situación:

(8) Luego de la aprobación en los últimos doce meses del Matrimonio Igualitario en Colombia, México y Estados Unidos, y de una opinión pública crecientemente favorable, la única discusión 
real sobre este punto en Chile es cuántos años se demorará en aprobarse, no si efectivamente ocurrirá o no.

Como se puede apreciar, en (8) Larraín destaca la aprobación del Matrimonio Igualitario en varios países, que son presentados en una enumeración, lo que se ha producido en un plano temporal de doce meses. A eso se debe añadir que no se trata de una posición favorable la que tiene la opinión pública, sino de una opinión crecientemente favorable, lo que entrega aún mayor valor a esa evaluación positiva respecto al Matrimonio Igualitario. El recurso de autenticidad hacia el final de la cláusula por medio del adjetivo real, como recurso de FOCO, refuerza la idea de inminencia.

En concreto, entonces, Larraín utiliza los recursos de gradación para dar fuerza a sus ideas, mientras que Góngora no tan solo refuerza las propias, sino que también disminuye las ajenas, como se verá más adelante que también ocurre con recursos de APRECIACIÓN.

\subsection{Compromiso heteroglósico y monoglósico en los textos}

Un aspecto clave en el análisis realizado y que sirve para explorar los posicionamientos y/o alineaciones ideológicas de los hablantes, sin duda, es el COMPROMIso como subsistema desarrollado en el modelo de VALORACIÓN. El subsistema de COMPROMiso, a través de las categorías de heteroglosia y monoglosia, nos permite verificar la incorporación o no de voces alternativas dentro del discurso del hablante. La ausencia de reconocimiento de voces alternativas y/o la incorporación de dichas voces podría dar luces acerca de la alineación ideológica del hablante y del soporte argumentativo que se emplea en las cartas al director que conforman el corpus.

En Góngora se advierte de forma predominante un compromiso monoglósico dogmático construido lingüísticamente a través de declaraciones en las que se emplean procesos del tipo relacional.

(9) [El matrimonio heteronormado] Es la instancia por excelencia que funda la familia.

(10) [El matrimonio heteronormado] Es una "construcción" biológica ajena a toda intervención intelectual.

(11) Siendo el orden matrimonial superior a toda argumentación racional. 
En (9), (10) y (11) podemos observar que el hablante sostiene su argumentación respecto al matrimonio entre personas heterosexuales en creencias incuestionables articuladas discursivamente mediante construcciones declarativas con proceso relacional. Se instalan, a través de esos recursos, verdades inamovibles que no dejan espacio para voces alternativas o posibilidades de cuestionamiento. Tampoco se puede advertir argumentos que sostengan dichas afirmaciones que parecen categóricas y absolutas. Góngora nos habla desde una verdad única: es así solo porque es así y ha sido siempre.

Los ejemplos anteriores, por lo tanto, corresponderían a un COMPROMISO monoglósico por aserción de carácter dogmático, matizado con otros recursos valorativos descritos en la grilla (ver anexos) que legitiman un comportamiento.

Por su parte, en el discurso de Larraín podemos observar la aparición frecuente de otro tipo de recursos. En efecto, Larraín se ampara en diversas fuentes (fundamentalmente históricas) para cuestionar esas verdades inamovibles planteadas por Góngora y para -de paso- validar el Matrimonio Igualitario.

(12) La historia nos muestra que, contrario a lo que algunos puedan pensar, tanto la homosexualidad como la formalización de las relaciones entre personas del mismo sexo forman parte no solo de la historia de la humanidad, sino también de la de nuestra propia cultura occidental, y no son síntomas de la posmodernidad.

(13) Existen registros de matrimonios entre personas del mismo sexo ya en la antigua Mesopotamia, varios siglos antes de Cristo.

(14) En la Roma imperial, era algo tan común, que incluso dos emperadores romanos, Nerón y Heliogábalo, estuvieron comprometidos en uniones del mismo sexo.

En (12) se puede apreciar un COMPROMISO heteroglósico de expansión dialógica de reconocimiento al incorporar la voz de la historia sin desmarcarse de la misma (La historia nos muestra...) y de esta manera se busca contravenir el dogmatismo histórico de Góngora (...contrario a lo que algunos puedan pensar...) por una parte, y por otra, validar la existencia histórica de la formalización de las relaciones entre personas del mismo sexo.

En (13) podemos observar que se construye un compromiso heteroglósico de contracción dialógica de proclamación y respaldo, 
pues emerge el recurso de la evidencialidad (existen registros). Argumentativamente, Larraín en este caso recurre a evidencia histórica para justificar y legitimar el Matrimonio Igualitario y para reprobar y deslegitimar el discurso monoglósico dogmático de Góngora.

En (14) el hablante nos lleva a la Roma Imperial para situar en ella relaciones formalizadas entre personas del mismo sexo entre connotados personajes de la época. Con esto se evidencia nuevamente un compromiso heteroglósico de contracción dialógica de proclamación y respaldo que recurre a la evidencia histórica como fuente articuladora de la argumentación favorable al Matrimonio Igualitario.

En suma, el recurso de las referencias históricas resulta crucial en las líneas argumentativas de ambos textos, pero se articulan lingüísticamente de distinta manera. Mientras la argumentación de Góngora descansa en expresiones declarativas que plantean verdades indiscutibles y por tanto expresan dogmas de fe, Larraín en su argumentación emplea la historia de manera heteroglósica de forma tal de que sirva como respaldo del punto que quiere plantear. El empleo del compromiso heteroglósico al parecer otorga mayor fuerza a la argumentación al incorporar evidencia de la historia.

\subsection{Las verdades incuestionables e inamovibles}

Desde el análisis, y una vez revisadas las co-ocurrencias de patrones, el sistema de APRECIACIón permite vislumbrar algunas ideas que subyacen en cada discurso. En particular, aquella que parece guiar la estructuración de ambos discursos es la noción de conflictividad que se le asocia al Matrimonio Igualitario.

En efecto, el discurso de Góngora continuamente realiza apreciaciones de Integridad, realzando el valor ético y moral del matrimonio heteronormado, del cual, a su parecer, carecería un potencial Matrimonio Igualitario. Para esto, Góngora articula su texto en base a criterios dogmáticos que validan su idea de matrimonio ideal, para lo cual legitima constantemente al matrimonio heteronormado por medio de las instituciones. Algunas cláusulas que permiten vislumbrar esto son las siguientes:

(15) [El mérito que legitima al matrimonio heterosexual es] Actuar conforme al orden establecido por la naturaleza propiamente humana y al comportamiento histórico legitimado durante milenios por la humanidad. 
(16) Posteriormente, el Estado [al matrimonio heterosexual] lo sancionó y la Iglesia Católica sacramentó.

Como se puede observar, para el caso de (15) el autor de la columna legitima el matrimonio heterosexual utilizando como argumento que este ha sido avalado por la misma historia y la conducta de la sociedad civil durante esos milenios. Asimismo, presenta como evidencia histórica la acción de instituciones que han adquirido valor en la misma organización civil: en el caso de (16), el Estado y la Iglesia Católica. Las apreciaciones aquí presentes, que tienen al matrimonio heteronormado como objeto positivamente evaluado, manifiestan a la vez un poder alto y una conflictividad baja, lo que podría manifestar la noción de incuestionabilidad que tiene para el autor la institución matrimonial tal como es actualmente en Chile.

De la misma forma, el mismo Góngora se refiere a la idea de Matrimonio Igualitario (y no como potencial institución) con un poder bajo y con una conflictividad alta. Algunos ejemplos son los que siguen:

(17) No existe. Es insostenible. Porque la posibilidad de un matrimonio y familia diferente es una invención proveniente de una posición relativista, individualista, que reacciona contra la realidad, contrariando verdades inamovibles.

(18) Son quienes aseguran, sin ninguna doctrina filosófica de respaldo, que las instituciones son construcciones culturales que pueden variar a la libre elección.

Para (17) y (18), Góngora reduce el poder de quienes defienden el Matrimonio Igualitario por medio de apreciaciones en (17) y juicios en (18), incluso dando las mismas valoraciones negativas tanto a la posición ideológica como a las personas que la sostienen. En este sentido, la posición del autor se resume en que los que defienden el Matrimonio Igualitario son relativistas porque no tienen ninguna doctrina filosófica de respaldo. De esta forma, reduce su poder para deslegitimar no tan solo la causa, sino también a los que la asumen como propia. Además, lo anterior se suma a que los tilda de reaccionarios, pues se oponen a la verdad misma tal como es y debe ser. En consecuencia, la institución del matrimonio heteronormado es incuestionable porque:

(19) Es una afirmación de principio, una verdad.

Esta última cláusula resume en parte aquello que se ha presentado recientemente: la legitimación se realiza elevando el poder y, en 
consecuencia, disminuyendo la conflictividad; es decir, patentando que no debiera haber debate alguno sobre algo que no se debiera cuestionar. Esto adquiere mayor relevancia al considerar la presencia de una monoglosia por aserción que no permite que voces alternativas ingresen al discurso, más aún por la presencia de una intensificación alta debido a lo que Hood (2010) denominaba un recurso de repetición, aunque en este caso no por elementos léxicos, sino netamente a la proposición que se repite constantemente cláusula a cláusula (para más detalles, ver anexos).

La postura de Larraín, en tanto, se presenta en su discurso mediante el cuestionamiento a aquellas verdades inamovibles. Para esto, el autor hace uso de la evidencia histórica, al igual que Góngora, pero de forma tal que la utiliza para dar cuenta de los procesos de cambio históricos que hoy en día se consideran esenciales en las sociedades desarrolladas y democráticas. El siguiente ejemplo ilustra estas ideas:

(20) De hecho, fueron justamente cuestionamientos críticos a esos comportamientos legitimados los que posibilitaron los avances históricos que sentaron las bases de las sociedades democráticas modernas, como el fin de la esclavitud, la libertad de culto, el fin de la segregación racial o el voto femenino.

En efecto, se evidencia en (20) la diferencia que se produce entre aquellos comportamientos legitimados históricamente evaluados negativamente y los cuestionamientos críticos, evaluados positivamente. Estos últimos, además, en el discurso de Larraín se comportan de forma variada al revisar el poder y conflictividad. En particular, la ejemplificación de los logros de aquellos procesos sociales refuerza la reducción de la conflictividad, así como también lo intentaba Góngora por medio de la apelación a las instituciones. Asimismo, Larraín otorga un poder alto constantemente a la evidencia histórica presentada, puesto que demuestra el potencial de la acción de la sociedad para resguardar y mejorar los derechos civiles.

Junto con lo anterior, en (21) Larraín reduce el poder alto que Góngora le atribuía a la naturaleza como elemento que legitimaba al matrimonio heteronormado como única institución viable para consagrar las uniones civiles. Esto, debido al potencial de las parejas conformadas por personas de distinto sexo para procrear, reduciendo el concepto de familia únicamente a este tipo de pareja. Como forma de dar con ese resultado, 
Larraín precisa que una ley de Matrimonio Igualitario no pretendería de ninguna forma responder a aquella consigna:

(21) En cuanto a la naturaleza, la única regla inamovible - y que no pretende ser contestada por ninguna ley de Matrimonio Igualitario- es que la procreación se produce a partir de un gameto femenino y uno masculino.

En síntesis, la legitimidad que otorga Góngora al matrimonio heteronormado -y la consecuente deslegitimidad a la idea de Matrimonio Igualitario- descansa en la noción que establece que la naturaleza instituyó un único tipo de matrimonio y que esa pauta ha sido validada históricamente durante siglos por parte de la humanidad, lo que se observa en la legitimidad que las instituciones le han otorgado. Ante las voces que apoyan la inclusividad en esta institución y las recientes aprobaciones en otros países, Góngora opta por reducir la fuerza de estos menospreciando primeramente a quienes se encuentran a favor de esas causas antes que a las causas mismas. Para esto, otorga poder a las instituciones y, así, comprime la conflictividad. Esto mismo se observa por medio de los recursos de GRADACIÓN, pues eleva la fuerza de su posición y disminuye la de su contraparte. Por su parte, Larraín cuestiona esos principios otorgándole un poder alto a la evidencia histórica a favor de causas previas que también involucran los derechos humanos, es decir, sitúa la causa que defiende como un proceso histórico comparable con otros eventos y movimientos sociales. Asimismo, esa consideración se realiza a partir de los principios que rigen las sociedades democráticas modernas, por lo que su discurso no tan solo se articula desde el pasado lejano.

\section{Conclusiones y proyecciones}

Los textos que conforman el corpus recurren a distintas estrategias valorativas para alcanzar sus objetivos políticos. En el caso de la carta que cuestiona la noción de Matrimonio Igualitario, Góngora se refiere al matrimonio como institución y para aludir al Matrimonio Igualitario lo representa discursivamente como idea. Por su parte, Larraín se refiere al matrimonio en general y al Matrimonio Igualitario como instituciones y, como tales, creadas y validadas por la cultura y no necesariamente de carácter natural e inmutable.

El subsistema de GRADACIÓN se aprecia en el texto de Góngora en su variante FUERZA por intensificación baja y resulta clave en la 
construcción de la argumentación que cuestiona la noción de Matrimonio Igualitario. En concreto, mediante recursos de GRADACIÓN intenta invalidar los posicionamientos favorables al Matrimonio Igualitario al disminuir el volumen semántico de los argumentos de quienes buscan conquistar esa institución. Larraín, en cambio, intensifica de forma alta las valoraciones referidas a fuentes históricas y argumentos para validar el Matrimonio Igualitario como institución.

El compromiso heteroglósico del texto de Larraín podría interpretarse por el hecho de que es una respuesta al texto de Góngora. El compromiso heteroglósico expande el dialogismo para incorporar voces provenientes de fuentes históricas que sirven como respaldo tanto para la propuesta de Matrimonio Igualitario, como para justificar su valor social y cultural.

El discurso de Góngora se basa de manera prominente en un compromiso monoglósico de aserción, a través del cual busca posicionar verdades incuestionables respecto a la institución del matrimonio. Esas verdades incuestionables e inamovibles corresponden a uno de los tópicos más referido en ambos textos. Góngora utiliza esas verdades incuestionables e inamovibles como argumentos para validar y legitimar el matrimonio heterosexual, mientras que Larraín las cuestiona en tanto impedimento para avanzar en derechos civiles para la diversidad sexual, derechos que responden al imperativo ético de un tratamiento igualitario.

Góngora expresa una valoración de APRECIACIÓN positiva para esas verdades inamovibles, mientras que Larraín articula una valoración de APRECIACIÓN negativa de aquéllas. En la fundamentación de tales evaluaciones, Góngora hace uso del aumento de poder a las instituciones para volverlas incuestionables y, así, menos conflictivas y, por tanto, no susceptibles de ser problematizadas. Por su parte, Larraín realiza el mismo procedimiento, pero hacia la evidencia histórica más reciente, respecto a los cambios sociales conquistados desde precisamente la problematización de esas verdades incuestionables.

Al comparar ambos textos desde el punto de vista evaluativo se advierte una contraposición entre un discurso monoglósico dogmático de Góngora (basado en un marcado compromiso monoglósico) y un discurso heteroglósico de Larraín, fundado en evidencia histórica a la que recurre como fuente autoral y como GRADACIÓN de fuerza de expansión temporal y espacial para dar cuenta de la magnitud de los 
hechos históricos correspondientes a las fuentes y la importancia de esos acontecimientos históricos en la comprensión de los procesos de cambio social que buscan la inclusión.

En cuanto a la categoría JUICIO del sistema de ACTITUD, en el texto de Góngora las valoraciones de juicio van dirigidas a los actores sociales que abogan por el Matrimonio Igualitario; en cambio, en el discurso de Larraín advertimos valoraciones éticas respecto al funcionamiento de las instituciones políticas y su responsabilidad en el avance de una sociedad genuinamente democrática.

En síntesis, el corpus revisado se trata de una confrontación de posicionamientos ideológicos que reflejan, en el caso del texto de Góngora, una concepción tradicional respecto a la institución del matrimonio y, en el texto de Larraín, una concepción desafiante de la tradición hegemónica respecto al matrimonio. La posibilidad de revisar el diálogo entre estos discursos permite, a su vez, verificar cómo estrategias valorativas similares son empleadas con propósitos políticos distintos. Esas estrategias valorativas, en definitiva, construyen la línea argumental de ambos posicionamientos ideológicos para influir en la discusión pública acerca del Matrimonio Igualitario.

Finalmente, debemos advertir que los resultados de nuestro trabajo reflejan la postura de dos personas particulares que, pese a su rol institucional, no necesariamente representan un sentir compartido. Sin embargo, si bien se trata de una exploración parcial respecto a la discusión pública sobre el Matrimonio Igualitario, vale destacar que el mismo soporte masivo en que estos discursos se presentan permite efectivamente observar reacciones discursivas que expresan alineación ideológica. En este sentido, creemos que es clave revisar con un corpus más exhaustivo cómo se podrían presentar estos mismos patrones valorativos, tanto en géneros similares como en otros tipos de textos de ciberprensa. Precisamente, la investigación en la que se enmarca este trabajo busca rastrear los patrones valorativos mediante los cuales se representa la discusión sobre el matrimonio igualitario y otros hitos significativos para las organizaciones políticas de la diversidad sexual ${ }^{9}$.

\footnotetext{
9 Sugerimos revisar Araya, C. (2019). Representaciones discursivas: valoraciones a la comunidad gay en comentarios de ciberprensa chilena. Revista de Estudios Lingüísticos y Literarios Árboles y Rizomas. Facultad de Humanidades. Universidad de Santiago de Chile. (En prensa).
} 


\section{Referencias bibliográficas}

Cadem. (2014). Track semanal de Opinión Pública. Estudio, 86. Disponible en: http://plazapublica.cl/wp-content/uploads/658799.pdf

Fairclough, N. (1992). Discourse and social change. Cambridge: Polity Press.

Fairclough, N. (1995). Critical Discourse Analysis. Londres: Longman.

Fairclough, N. (2013). Critical discourse analysis. The critical study of language. New York: Routledge. Second Edition.

Fairclough, N. (2008). El análisis crítico del discurso y la mercantilización del discurso público. En Discurso y Sociedad, 2, 170-185.

Farías, M. (2015). Análisis crítico multimodal y percepción del discurso homofóbico en el paisaje sociosemiótico de Santiago de Chile. En Revista ALED. Edición homenaje 20 años.

Fluxá, R. (2014). Solos en la noche. Zamudio y sus asesinos. Santiago de Chile: Catalonia.

Halliday, M. A. K. (1978). Language as a Social Semiotic: The Social Interpretation of Language and Meaning. London: Arnold.

Hood, S. (2010). Appraising Research: Evaluation in Academic Writing. London: Palgrave Macmillan.

Kaplan, N. (2004). Nuevos desarrollos en el estudio de la evaluación en el lenguaje: la teoría de la valoración. Boletín de Lingüística, 22, 52-78.

Larraín, A. y Medina, L. (2007). Análisis de la enunciación: distinciones operativas para un análisis dialógico del discurso. Estudios de Psicología, 28(3), 283-301.

Martin, J. y Rose, D. (2007). Working with discourse. London: Continuum.

Martin, J. y White, P. (2005). The Language of Evaluation. Appraisal in English. Ney York: Palgrave Macmillan.

Oteíza, T. (2009). Solidaridad ideológica en el discurso de la historia: Tensión entre orientaciones monoglósicas y heteroglósicas. Revista Signos, 42(70), 219-244.

(2017). The Appraisal Framework and discourse analysis. En The Routledge Handbook of Systemic Functional Linguistics. Tom Barlett y Gerard O’ Grady (Eds.) Capítulo 28, 457-472. 
Oteíza, T. y Pinuer, C. (2012). Prosodia valorativa: construcción de eventos y procesos en el discurso de la historia. Discurso y Sociedad, 6(2), 418-446.

Oteíza, T., Henríquez, R. y Canelo, V. (2018). Language resources to negotiate historical thinking in history classroom interactions. Linguistics and Education, 47, 1-15.

Saussure, F. (1945). Curso de Lingüística General. Buenos Aires: Losada. Thompson, G. y Hunston, S. (2000). Evaluation: An Introduction. En Hunston, S. y G. Thompson. (Eds.). Evaluation in Text. Oxford: Oxford University Press.

Volóshinov, V. (2009). Hacia una filosofía del lenguaje. En El marxismo y la filosofía del lenguaje. Buenos Aires: Godot. Segunda Parte, 75-170.

White, P. (2004). Un recorrido por la teoría de la valoración. Disponible en: www.grammatics.com/appraisal/SpanishTranslationAppraisalOutline.pdf.

White, P. (2010). Talking Bakhtin seriouly: dialogic effect in written, mass comunicative discourse. En Japanese Journal of Pragmatics, 12, 37-53. 